\title{
Effect of Asphyxia on Thrombotest Values in Low Birthweight Infants
}

\author{
W. J. APPLEYARD and D. G. COTTOM \\ From the Neonatal Research Laboratory, St. Thomas's Hospital, London S.E.1
}

\begin{abstract}
Appleyard, W. J., and Cottom, D. G. (1970). Archives of Disease in Childhood, 45, 705. Effect of asphyxia on thrombotest values in low birthweight infants. Thrombotest was used as a measure of coagulation status in 55 low birthweight infants. The initial levels were similar in both babies who were asphyxiated at birth and in those who had uncomplicated deliveries. On the other hand, 24 hours after giving vitamin $\mathrm{K}_{1}$, a rise in the mean percentage thrombotest activity was confined to the normal delivery group. No significant rise occurred in the babies who suffered from hypoxia. It is suggested that fresh frozen plasma should be given particularly to asphyxiated low birthweight infants in an effort to diminish their liability to haemorrhage.
\end{abstract}

It is well recognized that the newborn low birthweight infant has an impaired coagulation status (Oski and Naiman, 1966). Factors II, VII, and X in particular tend to be lower than in normal adults (Cade, Hirsh, and Martin, 1969), either due to hepatic immaturity, or vitamin $\mathrm{K}$ deficiency (Aballi and De Lamerens, 1962). Van Creveld, Paulsen, and Teng (1952) showed that anoxia accentuated these defects. As the asphyxiated low birthweight infant is particularly at risk from cerebral haemorrhage (Towbin, 1968) correction of prolonged coagulation time seems to be urgent. Vitamin $\mathrm{K}$ is widely prescribed for this purpose, but its efficacy has been doubted (Denton, 1961). Using the thrombotest (Owren, 1959) which reflects any deficiency in factors II, VII, X, and perhaps IX, we have studied the initial coagulation status of 55 low birthweight infants and the response to Vitamin $\mathrm{K}_{1}$ in two groups of normal and asphyxiated low birthweight infants.

\section{Material and Methods}

55 low birthweight infants (under 2500 g.) were assessed by the thrombotest at birth and 24 hours after an intramuscular injection of $1 \mathrm{mg}$. vitamin $\mathrm{K}_{\mathrm{I}}$ (Konakion).

The infants were divided into two groups. Normal low birthweight infants were defined as those infants who had established regular respiration by 3 minutes, and the asphyxiated group were defined as those infants who had,

Received 17 April 1970. (a) failed to establish regular respiration within 3 minutes of birth (18 cases), or (b) subsequently suffered prolonged periods of apnoea necessitating the assistance of intermittent positive pressure ventilation ( 4 cases).

The thrombotest was performed on capillary or citrated venous blood up to 6 hours from birth. 0.05 $\mathrm{ml}$. samples were added to $0.25 \mathrm{ml}$. aliquots of the reagent, reconstituted in either distilled water or calcium chloride. Careful temperature control $\left(36^{\circ}-38^{\circ} \mathrm{C}\right.$.) was maintained in a portable water bath. The clotting time was noted and the percentage coagulation activity read from the correlation curves specific for each type of sample and batch of reagent. A level of $10 \%$ activity has been regarded in adults as the lower limit of safety to avoid spontaneous bleeding (Owren, 1959).

$\mathrm{The} \mathrm{Hb}$ concentration was measured in 20 infants and a correction should be made in the percentage activity for this of up to a factor of $1 \cdot 5$. However, this correction did not alter the trend of our results, so the percentage activity is presented unadjusted, in line with those previously published by other workers (Wefring, 1962; Gray, Ackerman, and Frazer, 1968).

The acid-base status was assessed in 15 infants about one hour after delivery by the standard Astrup technique (James, 1959).

\section{Results}

Initial thrombotest levels. The initial thrombotest values in the 55 low birthweight infants (Table I) revealed only $4(7 \%)$ with levels under $10 \%$ activity. This is similar to the control group of 43 full-term normal infants in whom $3(7 \%)$ had low values. The mean initial thrombotest value of 
TABLE I

Initial Thrombotest Values in Full-term and Low Birthweight Infants

\begin{tabular}{l|c|c|c}
\hline & No. & $\begin{array}{c}\text { Mean \% } \\
\text { Thrombotest } \\
\text { and Range }\end{array}$ & $\begin{array}{c}\text { No. of Cases } \\
\text { with Less than } \\
10 \% \text { Activity }\end{array}$ \\
\hline Full-term & 43 & $27(5-48)$ & 3 \\
$\begin{array}{l}\text { Low birthweight } \\
\begin{array}{l}\text { Normal } \\
\text { Asphyxiated }\end{array}\end{array}$ & 30 & $22(5-45)$ & 1 \\
\hline
\end{tabular}

the group of 25 low birthweight asphyxiated infants was $19 \%$ which was lower than that of the 30 normal low birthweight infants (22\%). 3 out of the 25 asphyxiated infants (12\%) had initial thrombotest values under $10 \%$, while only 1 of the otherwise normal low birthweight infants and 3 of the 43 full-term infants $(7 \%)$ had values under $10 \%$ activity. These differences are not significant. Of the infants with thrombotest values under $10 \%$, one had suffered a period of anoxia of over 20 minutes and the other 3 belonged to a subgroup of 5 postmature low birthweight infants.

Four of the infants were both premature and small-for-dates (under the 10th centile). Their thrombotest values $(21,22.5 \%, 13 \%$ and $17 \%$ ) were in the same range as the normal weight-fordates infants.

Response to vitamin $K_{1}$. The response to an intramuscular injection of $1 \mathrm{mg}$. vitamin $K_{1}$ was studied in 43 low birthweight infants (Table II). Low birthweight infants who had not suffered any hypoxia at birth were compared with 20 who had suffered moderate to severe birth asphyxia. There was a significant rise in the mean thrombotest levels in the non-asphyxiated group ( $p=0.01)$ but no significant rise in the hypoxic group. The asphyxiated group contained more infants of very

TABLE II

Response of Thrombotest Levels to Vitamin $K$ in Normal and Asphyxiated Low Birthweight Infants

\begin{tabular}{|c|c|c|c|}
\hline \multirow[b]{2}{*}{ Infants } & \multirow[b]{2}{*}{ No. } & \multicolumn{2}{|c|}{ Mean \% Thrombotest } \\
\hline & & $\begin{array}{c}\text { At Birth } \\
\text { and Range }\end{array}$ & $\begin{array}{l}24 \text { Hours After } \\
\text { Vitamin } \mathrm{K}_{1} \\
\text { and Range }\end{array}$ \\
\hline $\begin{array}{l}\text { Normal } \\
\text { SE }\end{array}$ & 23 & $\begin{array}{l}23 \cdot 1(12-35) \\
1 \cdot 8\end{array}$ & $\begin{array}{l}37 \cdot 7(21-90) \\
3 \cdot 7\end{array}$ \\
\hline $\begin{array}{l}\text { Asphyxiated } \\
\text { SE }\end{array}$ & 20 & $\begin{array}{l}19 \cdot 1(5-46) \\
2 \cdot 1\end{array}$ & $\begin{array}{l}21 \cdot 3(5-38) \\
1 \cdot 7\end{array}$ \\
\hline
\end{tabular}

low birthweight, and in order to discover whether this difference might be due to immaturity, two groups of infants, matched for birthweight and gestation, are compared in the Fig. An identical

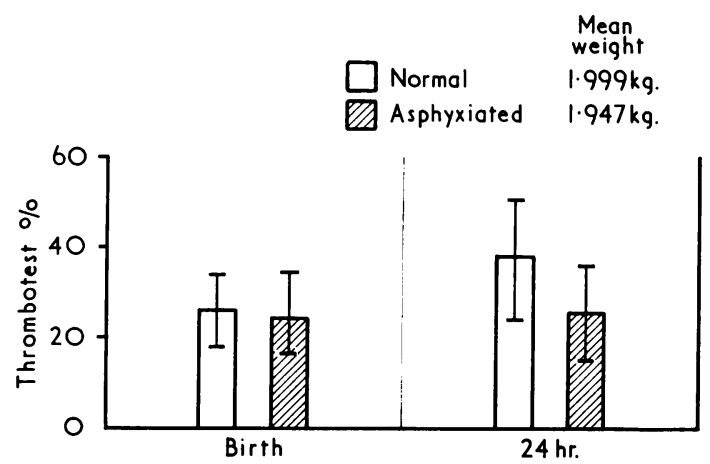

FIG. - Effect of $1 \mathrm{mg}$. vitamin $K$ on thrombotest activity in normal and asphyxiated low birthweight infants during first 24 hours after birth.

trend is shown, which suggests that hypoxia rather than immaturity was the main factor in determining the response to vitamin $\mathrm{K}$.

Of the 4 low birthweight infants requiring assisted ventilation, 3 died. All had hyaline membrane disease. One of these also suffered from a cerebral haemorrhage. This infant had an initial thrombotest of $24 \%$ which dropped to $10 \%$ over the first 24 hours. There was no significant change in the thrombotest values of the other 2 infants who died. All the non-asphyxiated low birthweight infants survived.

Relation of thrombotest values to acid-base status. The acid-base status was measured in 15 of the low birthweight asphyxiated infants about one hour after birth. Bicarbonate levels at this time have been taken as a guide to the degree of perinatal asphyxia. There was no relation between the standard bicarbonate and thrombotest levels. At a $p \mathrm{H}$ above 7 there was also no relation between the $p \mathrm{H}$ values and the thrombotest activity. Three infants who had a $\mathrm{pH}$ of under 7 had percentage levels of under $5 \%, 12 \cdot 5 \%$, and $13 \%$.

\section{Discussion}

Gray et al. (1968) found that about half their asphyxiated low birthweight infants defined by similar criteria to our own had thrombotest levels under $10 \%$. We found only $12 \%$ in our smaller series. This difference is difficult to explain, but may be due to the time after birth when the samples 
were taken. The fact that there is no relation between the standard bicarbonate level, estimated at about 1 hour after birth, and the thrombotest activity confirms that the initial thrombotest levels were not much influenced by birth asphyxia causing moderate metabolic acidosis in low birthweight infants. These findings are consistent with those of Markarian et al. (1967) who showed that at least 18 hours of hypoxia were necessary to alter the coagulation factors in newborn puppies.

No significant difference could be noted between the initial thrombotest values of the 55 low birthweight infants and the control group of 43 normal full-term infants, and these values in turn are similar to those previously reported by Wefring (1962) and by Gray and Smith (1966). We doubt the value of taking an arbitrary level of $10 \%$ thrombotest activity alone as an index of increased risk for cerebral haemorrhage, in infants of low birthweight, particularly if uncorrected for haemoglobin concentration.

The response to vitamin $K_{1}$ over 24 hours in the mean thrombotest levels of the normal low birthweight infants $(23 \cdot 1 \%-37 \cdot 7 \%)$ was similar to the full-term infants reported by Gray et al. (1968), but there was no significant rise in the mean levels in the asphyxiated group, illustrating that even a moderate degree of asphyxia may either impair the response of the liver to vitamin K (Aballi, 1965) or cause increase in the consumption of the coagulation factors.

This difference between the normal and asphyxiated groups remained valid when allowance had been made for birthweight and gestation. It seems that it is the group of asphyxiated low birthweight infants who require fresh frozen plasma to restore and maintain their coagulation status. Our preliminary results in treating these infants (Appleyard, 1969) confirm those of Gray et al. (1968). 9 out of 10 infants showed improvement in their thrombo- test levels over the 24-hour period after an infusion of $10 \mathrm{ml} . / \mathrm{kg}$. fresh frozen plasma.

We would like to thank the sisters, midwives, and nursing staff in the Premature Baby Units of the St. Thomas's Hospital Group for their interest and co-operation in this study, and Miss Angela Brinton for technical assistance. The work was supported by a grant from the Worshipful Company of Dyers.

\section{REFERENCES}

Aballi, A. J. (1965). The action of vitamin $\mathrm{K}$ in the neonatal period. Southern Medical fournal, 58, 48.

- , and De Lamerens, S. (1962). Coagulation changes in the neonatal period and in early infancy. Pediatric Clinics of North America, 9, 785.

Appleyard, W. J. (1969). Research Report to the Worshipful Company of Dyers, London.

Cade, J. F., Hirsh, J., and Martin, M. (1969). Placental barrier to coagulation factors: its relevance to the coagulation defect at birth and to haemorrhage in the newborn. British Medical fournal, $2,281$.

Denton, R. L. (1961). Vitamin $\mathrm{K}$ for the newborn? Pediatric Clinics of North America, 8, 455.

Gray, O. P., Ackerman, A., and Frazer, A. J. (1968). Intracranial haemorrhage and clotting defects in low-birth-weight infants. Lancet, 1, 545 .

, and Smith, S. C. (1966). The thrombotest on the first day of life. Acta Paediatrica Scandinavica, 55, 563.

James, L. S. (1959). Physiology of respiration in newborn infants and in the respiratory distress syndrome. Pediatrics, 24, 1069.

Markarian, M., Lindley, A., Jackson, J. J., and Bannon, A (1967). Coagulation factors in pregnant women and premature infants with and without the respiratory distress syndrome. Thrombosis et Diathesis Haemorrhagica, 17, 585.

Oski, F. A., and Naiman, J. L. (1966). Hematologic Problems in the Newborn (Major problems in Clinical Pediatrics, vol. 4). Saunders, Philadelphia.

Owren, P. A. (1959). Thrombotest: a new method for controlling anticoagulant therapy. Lancet, $2,754$.

Towbin, A. (1968). Cerebral intraventricular hemorrhage and subependymal matrix infarction in the fetus and premature newborn. American fournal of Pathology, 52, 121.

Van Creveld, S., Paulsen, M. M. P., and Teng, S. K. (1952). Prothrombin and accelerator globulin in the plasma of newborns under normal and pathological conditions. Études Néo-natales, $1,87$.

Wefring, K. W. (1962). Hemorrhage in the newborn and vitamin $\mathrm{K}$ prophylaxis. Fournal of Pediatrics, 61, 686.

Correspondence to Dr. W. J. Appleyard, Department of Paediatrics, Guy's Hospital, London S.E.1. 